\title{
Early Detection Of Hypertension As An Effort To Prevent Disease Complications
}

\author{
Santy Irene Putri ${ }^{1}$, Aris Widiyanto ${ }^{2}$, Joko Tri Atmojo ${ }^{3}$, Asruria Sani Fajriah ${ }^{4 *}$ \\ ${ }^{1}$ Universitas Tribhuwana Tunggadewi Malang \\ ${ }^{2,3}$ STIKes Mamba’ul 'Ulum Surakarta, Surakarta \\ ${ }^{4}$ Institut Ilmu Kesehatan Strada, Kediri \\ *Email: sanifajriah@gmail.com
}

\begin{abstract}
Background: Measuring blood pressure is one way of early detection of the risk of hypertension, stroke and heart disease. Generally, in rural areas have lower access to health information and education than those in urban areas. Promotive and preventive efforts needed to increase public awareness to carry out early detection through measuring blood pressure regularly and adherence to taking medication regularly. This step is believed to be a form of controlling hypertension in the form of reducing the number of cases, complications, and deaths from hypertension. Methods: The method of activity to be carried out is a health check by measuring blood pressure and providing counseling which is carried out through lectures and discussions with the community about the signs and symptoms of hypertension, prevention of hypertension, and complications of hypertension. The activity was carried out on April 10, 2021 with the target of all members of the community in Wonosuko, Magelang, Central Java. Results: This activity was attended by a community of about 40 people. The implementation of this service went smoothly and the community was enthusiastic in examination and counseling activities. Most of the community felt the benefits of holding this activity because according to them, apart from getting knowledge about hypertension, the community also felt the benefits of checking blood pressure, and consulting various diseases related to complications due to hypertension. Conclusion: This community service activity has added insight and knowledge of communities about hypertension, especially about clinical symptoms, complications and also efforts to prevent hypertension. In addition, the public has also become more aware of the need to have their blood pressure checked at local health care facilities. In addition, communities' knowledge has also increased about several complications of hypertension which have been explained through consultation with the team of this activity.
\end{abstract}

Keywords: early detection, hypertension, prevention, disease complications;

\section{BACKGROUND}

Until now, hypertension is still a big challenge in Indonesia. Hypertension is a condition that is often found in primary health care. It is a health problem with a high prevalence, which is $25.8 \%$ in accordance with the 2013 Riskesdas data. Hypertension control is not adequate even though there are many effective drugs available. In Indonesia, there is a shift in eating patterns, which leads to fast food and preserved ones that we know are high in salt, saturated fat, and low fiber began to mushroom, especially in big cities in Indonesia.

By knowing the symptoms and risk factors for hypertension, it is expected that patients can do prevention and management by modifying diet/lifestyle or drugs so that complications that occur can be avoided (Kemenkes, 2018). Data from the World Health Organization (WHO) in 2015 showed that around 1.13 billion people in the world have hypertension, meaning that 1 in 3 people in the world is diagnosed with hypertension. The number of people with hypertension continues to increase every year, it is estimated that by 2025 there will be 1.5 billion people affected by hypertension, and it is estimated that every year 10.44 million people die caused by hypertension and its complications (Naidu et al., 2019). 
The Institute for Health Metrics and Evaluation (IHME) in 2017, stated that of the 53.3 million deaths in the world, $33.1 \%$ of deaths were caused by cardiovascular disease, $16.7 \%$ cancer, $6 \% \mathrm{DM}$ and endocrine disorders and respiratory tract infections down by $4.8 \%$. Data on causes of death in Indonesia 2016 obtained a total of 1.5 million deaths with the most common causes of death being cardiovascular disease $36.9 \%$, cancer 9.7\%, DM and endocrine diseases 9.3\% and tuberculosis 5.9\%. Riskesdas 2018 stated that the prevalence of hypertension based on measurement results in the population aged 18 years was $34.1 \%$, the highest was in South Kalimantan $(44.1 \%)$, while the lowest was in Papua (22.2\%). The estimated number of hypertension cases in Indonesia is 63,309,620 people, while the death rate in Indonesia due to hypertension is 427,218 deaths (IHME, 2019) (Mills et al., 2016) (Peltzer \& Pengpid, 2018).

The beginning of all complications is loss of balance. When high blood pressure rises, a person will have difficulty walking because the neck, and back will feel heavy and sore. This is caused by cholesterol levels which directly attack the balance nerves. As a result, the patient can fall unconsciously suddenly. The results of research by the World Health Organization (WHO) show that almost half of heart attacks are caused by high blood pressure. Blood pressure that continues to increase in the long term will cause the formation of a crust (plaque) which can narrow the coronary blood vessels.

Though coronary blood vessels are the path of oxygen and nutrients (energy) for the heart. As a result, the supply of essential substances (essential) for the life of heart cells is disrupted. In certain circumstances, high blood pressure can crack the crust (plaque) in the coronary arteries (Sharma, 2009). The loose debris can block blood flow, causing a heart attack. Patients with high blood pressure are twice as likely to suffer from coronary heart disease.

Blockage of blood vessels begins with a stroke. Stroke is a neuromuscular disorder that is influenced by blood vessels and is centered on the head. Usually, the nerves in the brain are not connected to the motor nerves so that the hand that is usually attacked cannot be moved because the blood flow does not flow to that part of the body. The worst part of blood vessel disorders caused by hypertension are complications in the kidneys and heart. Due to uneven blood flow, some of the body's organ functions will be affected. Blood disorders also affect the volume of blood flowing to the heart (Widiyanto et al., 2021) (Mozos, 2015) (Jones et al., 2014).

If not controlled, hypertension can cause complications such as heart disease, stroke, kidney disease, retinopathy (retinal damage), peripheral blood vessel disease, nerve disorders. The higher the blood pressure, the higher the risk of damage to the heart and blood vessels in large organs such as the brain and kidneys (De Boer et al., 2017) (Oparil et al., 2018). Based on the explanation of the conditions above, the team was moved to carry out community service activities in Wonosuko, Magelang.

\section{LITERATURE}

Definition Hypertension or high blood pressure is an increase in systolic blood pressure more than $140 \mathrm{mmHg}$ and diastolic blood pressure more than $90 \mathrm{mmHg}$ on two occasions measurement with an interval of five minutes in a state of sufficient rest / calm. An increase in blood pressure that lasts for a long time (persistent) can cause damage to the kidneys (kidney failure), heart (heart disease) coronary) and brain (causing stroke) if not detected early and received adequate treatment. Many hypertensive patients with low blood pressure controlled and the number continues to increase. 
Therefore, the participation of all parties, both doctors from various fields of specialization in hypertension, government, private and public society is needed so that hypertension can be controlled. According to the American Heart Association (AHA), Americans over the age of 20 years suffering from hypertension has reached up to 74.5 million people, but almost About 90-95\% of cases have no known cause. Hypertension is a silent killer where the symptoms can vary in each individual and are almost the same as other disease symptoms. The symptoms are headache/heaviness in the neck, nausea (vertigo), heart palpitations, lightheadedness, blurred vision, ears ringing (tinnitus), and nosebleeds (Fezeu et al., 2010).

Several studies have shown a significant relationship between non-communicable diseases with socio-demographic factors, behavior, physical conditions, and a history of other diseases. This matter in line with further analysis conducted on the results of Riskesdas 2007 by Ekowati Rahajeng and Sulistyo Tuminah. The study shows that hypertension is associated with with risk factors such as age, gender, education level, occupation, place residence, smoking behavior, alcohol consumption, consumption of vegetables and fruit, food consumption caffeine, and physical activity (Kemenkes, 2019).

Hypertension control aims to prevent and reduce the probability of illness, complications, and death. These steps can be grouped into pharmacological approaches and non-pharmacological. Pharmacological approach is a treatment effort to control blood pressure patients with hypertension which can be started from first-level health services such as: health center or clinic. Pharmacological therapy begins with a single drug that has a long-acting, so it can be given once daily and the dose is titrated. Next medicine may be added during the first few months of therapy.

Types of hypertension drugs consist of diuretics, beta blockers, angiotensin converting inhibitors Enzyme (ACE), and Angiotensin Receptor Blocker (ARB), Calcium Channel Blockers (CCB), and other antihypertensives. Some things that need to be considered in the treatment of hypertension include: Essential treatment is carried out to lower blood pressure with the aim of prolong life expectancy and reduce complications. Secondary treatment is more aimed at controlling the cause of hypertension. The choice of combination of anti-hypertensive drugs is based on the severity and response of the patient to the drug given.

Hypertension treatment is carried out for a long time, maybe even a lifetime life. Patients who successfully control blood pressure, then the administration of hypertension medication is given Puskesmas was given at the time of the visit, with a note that the new drug was given to the patient use for 30 days if no new complaints. Newly diagnosed patients, it is recommended to re-check 4 times a month or once a week, if systolic blood pressure $>160 \mathrm{mmHg}$ or diastolic $>100 \mathrm{mmHg}$ should be given combination therapy after the second visit (within 2 weeks) pressure blood cannot be controlled. Cases of hypertension or blood pressure that cannot be controlled after the first drug administration, then immediately given combination treatment therapy if it cannot be referred to the health facility higher (Kemenkes, 2019).

Hypertension can be treated with medication or by way of lifestyle modification. Lifestyle modifications can be made by limiting salt intake to no more than $1 / 4-1 / 2$ teaspoon (6 grams / day), lose weight, avoid caffeinated drinks, cigarettes, and beverages alcoholic. Exercise is also recommended for people with hypertension, can be in the form of walking, running, jogging, cycling for 20-25 minutes with a frequency of 3-5 times per week. Urgent also to get enough rest (6-8 hours) and control stress. For 
selection as well the use of hypertension drugs is recommended to consult a doctor your family.

There are also foods that should be avoided or limited by people with hypertension are Foods high in saturated fat (brain, kidney, lung, coconut oil, salary).

Foods that are processed using sodium salt (biscuits, crackers, chips and salty dry food). Canned food and drinks (sardines, sausages, corned beef, vegetables and canned fruits, soft drinks). Preserved foods (jerky, pickled vegetables/fruits, shredded, salted fish, pindang, dried shrimp, salted egg, peanut butter). Full cream milk, butter, margarine, mayonnaise cheese, and protein sources Animals that are high in cholesterol, such as red meat (beef/goat), yellow eggs, chicken skins). Seasonings such as soy sauce, maggi, shrimp paste, tomato sauce, chili sauce, tauco as well as other seasonings which generally contain sodium salt. Alcohol and foods containing alcohol such as durian, tape.

In Indonesia, there is a shift in eating patterns, which leads to fast food and preserved ones that we know are high in salt, saturated fat, and low fiber began to mushroom, especially in big cities in Indonesia. By knowing the symptoms and risk factors for hypertension, it is expected that patients can do prevention and management by modifying diet/lifestyle or drugs so that complications that occur can be avoided (Kemenkes, 2018).

\section{METHODS}

As an effort to prevent the occurrence of hypertension, to find out hypertension quickly and precisely so that people immediately get the right therapy, prevent further complications and the introduction of preventing complications due to hypertension, the community service activities that will be carried out in Wonosuko, Magelang on April 10, 2021 with the main target are people with an age range of 35-60 years are as follows: Provide education about the symptoms and signs of hypertension. Provide education about the prevention of hypertension. Provide education about the complication of hypertension

The method of activities to be carried out are as follows: Counseling, carried out through lectures and discussions with the community. Blood pressure checks assisted by health student. This community service activity is carried out with 1 stage of measuring high blood pressure, followed by the provision of counseling and education.

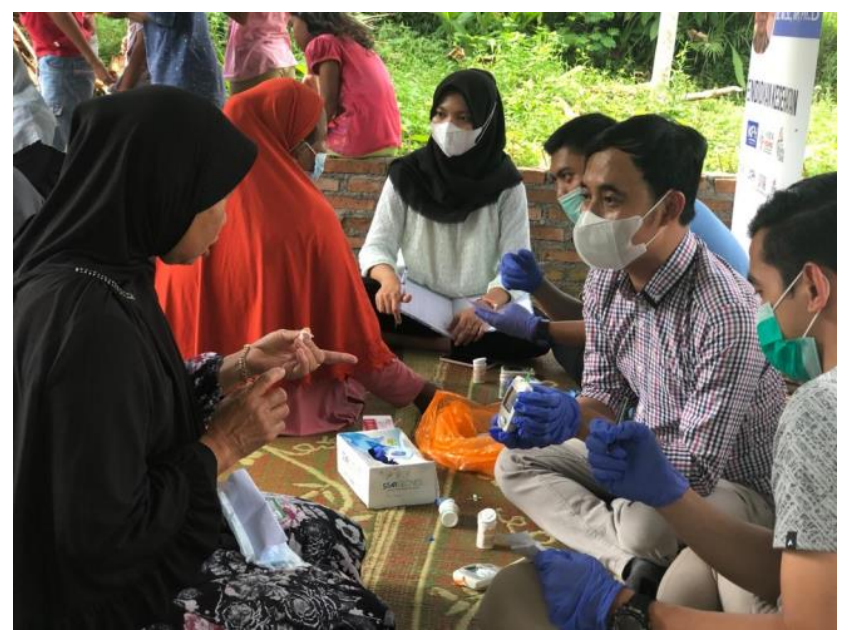

Picture 1. Counseling process 


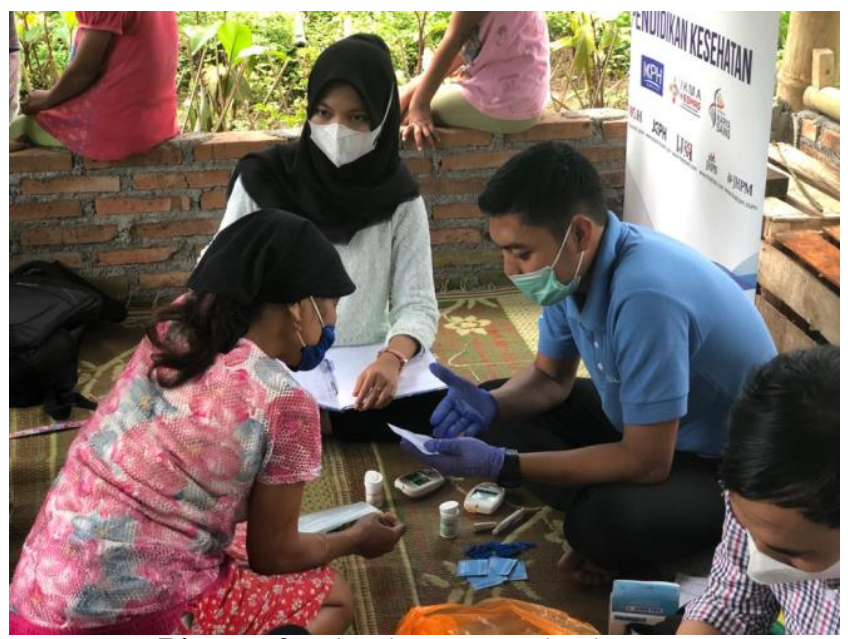

Picture 2. Blood pressure check process
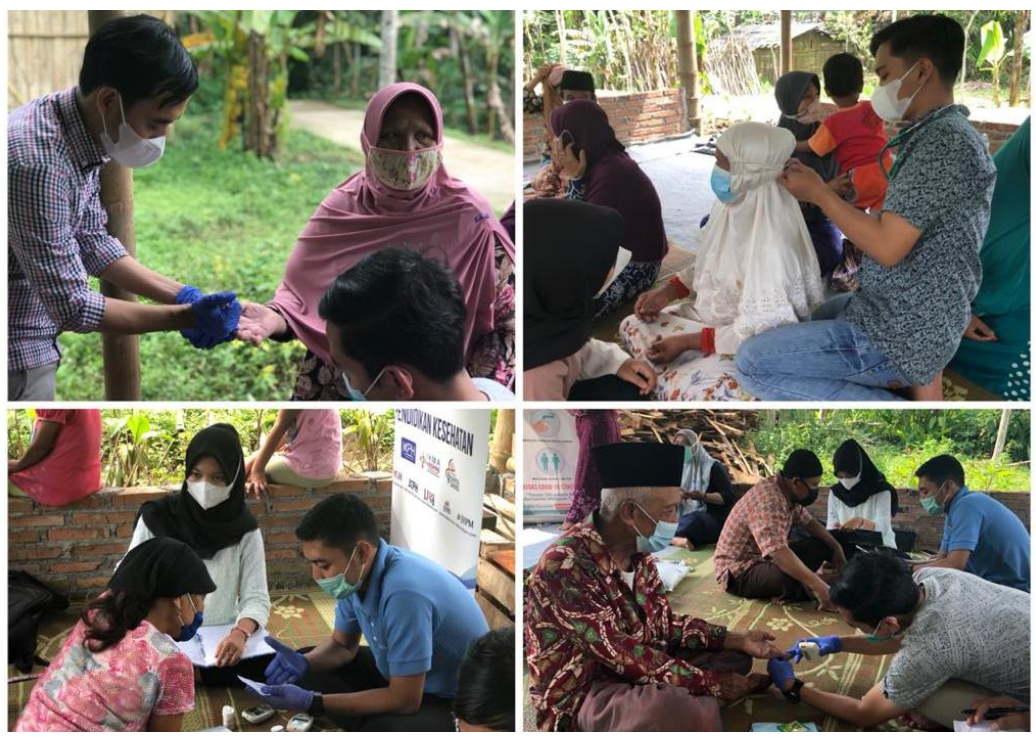

Picture 3. Uric acid and blood sugar check

\section{RESULTS}

The following are the characteristics of participants

Table 1. Characteristics of participants

\begin{tabular}{llcc}
\hline \multicolumn{1}{c}{ Characteristics } & \multicolumn{1}{c}{ Criteria } & n & \% \\
\hline Age & 36-45 tahun & 12 & 23 \\
& $46-55$ tahun & 22 & 42 \\
Gender & $56-65$ tahun & 18 & 35 \\
& Male & 20 & 39 \\
Level of education & Female & 32 & 61 \\
\cline { 2 - 3 } & Elementary School & 24 & 46 \\
& Junior High School & 8 & 14 \\
& High School & 9 & 17 \\
& Diploma & 11 & 19 \\
& Bachelor & 8 & 14 \\
\hline
\end{tabular}




\begin{tabular}{llcc}
\hline Characteristics & \multicolumn{1}{c}{ Criteria } & n & \% \\
\hline Occupation & Housewife & 27 & 52 \\
& Farmer & 20 & 38 \\
& Government employees & 2 & 4 \\
\multirow{3}{*}{ Income } & Private sector & 3 & 6 \\
& < Regional minimum wage & 34 & 65 \\
& $\geq$ Regional minimum wage & 18 & 35 \\
\hline
\end{tabular}

This activity was attended by the community with a total of about 52 people dominated by $46-55$ years old $(42 \%)$, female $(61 \%)$, level of education was elementary school $(46 \%)$, housewife $(52 \%)$, and income was mostly < regional minimum wage $(65 \%)$. The implementation of this service went smoothly. The activity began by providing brief counseling to service participants about hypertension, starting from the definition, clinical symptoms, disease complications and prevention and complications of hypertension.

In addition, it was also explained to the public about the importance of screening for hypertension so that appropriate treatment can be carried out immediately and further complications can be prevented. The team provided counseling to the people who were present when to seek treatment and immediately check blood pressure, so that the public knew the common symptoms of hypertension sufferers and immediately went to the local health center if these symptoms appeared.

From this outreach activity, it was seen that the participants who came had high enthusiasm, which was marked by the lively discussions that took place. Many participants asked about hypertension ranging from clinical symptoms to complications and prevention. In addition to asking about hypertension, community members also asked about other diseases, not even a few participants consulted about various diseases they were experiencing or experienced by their families.

\section{DISCUSSIONS}

Recently, the determination of a person's limit for hypertension has become more stringent, namely upper blood pressure $>130$ and lower blood pressure $>80 \mathrm{mmHg}$. The reason for the determination is because there are so many complications caused by hypertension such as stroke, shortness of breath, heart attack, heart failure, and kidney failure. The irony is that nowadays these complications occur without realizing it from a young age. One of the complications due to hypertension that lasts in the long term and is not controlled is chronic kidney disease (CKD) or kidney failure (Pugh et al., 2019) (Cha et al., 2020) (Drozdz \& Kawecka-Jaszcz, 2014).

It is very important to check and monitor blood pressure as an early detection of hypertension. Data released by the World Health Organization (WHO) in 2012 stated that hypertension was ranked first in the Global Burden of Disease, where disability or disease caused by hypertension was the highest. Blood pressure checks are needed that are carried out early in order to avoid various health risks that may occur through independent blood pressure checks (Campbell \& Niebylski, 2018) (Sheppard et al., 2020).

First, it is done by confirming the diagnosis to confirm blood pressure. Second, monitor therapy, where high blood pressure will be treated with two kinds of drugs to control blood. Third, improve monitoring of patient's blood pressure on a regular basis. Blood pressure monitoring should be done every two years for those over 20 years old 
and once a year for those over 40 years old. For those who are identified as having normal blood pressure, and who have cardiovascular risk factors such as diabetes, obesity, cholesterol, and heredity, it is also important to monitor blood pressure (MacDonald, 2015) (Petrie et al., 2018).

It is recommended that this check be done every day, in the morning and evening, taking two to three measurements at a time and recording the average. It is necessary to pay attention to the condition of the room so that it is calm with the back and arm sitting position supported, as well as the condition of the calibrated blood pressure checking tool or machine (Sharman et al., 2016) (Sreekanth et al., 2016).

Early detection is very easy to do and does not require special skills. It can be done independently or by a health worker (home blood pressure monitoring). Currently, there are many electronic blood swallows measuring devices that can be done independently which include the date. Measurement hours, activity during measurement, upper and lower blood pressure, and heart rate. The results of this record can be reported to primary health services for hypertension prevention efforts (Thimbleby, 2013).

\section{CONCLUSIONS AND SUGGESTIONS}

The community is enthusiastic about the implementation of blood pressure checks as an effort to prevent hypertension and its complications. Public awareness to carry out routine health checks is increasing. Increasing public knowledge about the consequences of uncontrolled hypertension.

In order to further improve the activities of early detection of risk factors for hypertension so that people with hypertension can be identified early and promote Germas activities at the local health center. Improving the implementation of health promotion and not only focusing on hypertension patients but also on healthy communities in the context of preventing hypertension. Advocacy for health promotion is further expanded.

\section{ACKNOWLEDGMENTS}

The team thanked Prof. Bhisma Murti, dr, MPH, MSc, PhD who gave full support to this community service activity.

\section{REFERENCES}

Campbell, N. R. C., \& Niebylski, M. L. (2018). Prevention and control of hypertension.

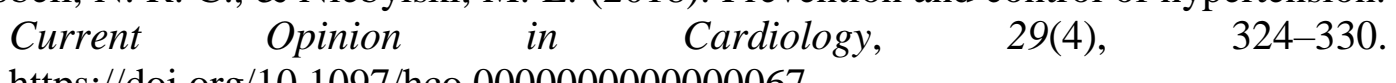
https://doi.org/10.1097/hco.0000000000000067

Cha, R. H., Lee, H., Lee, J. P., Kim, Y. S., Kim, S. G., \& Sahutoglu, T. (2020). The influence of blood pressure patterns on renal outcomes in patients with chronic kidney disease: The long-term follow up result of the APrODiTe-2 study. Medicine (United States), $1-7$. https://doi.org/10.1097/MD.0000000000019209

De Boer, I. H., Bangalore, S., Benetos, A., Davis, A. M., Michos, E. D., Muntner, P., Rossing, P., Zoungas, S., \& Bakris, G. (2017). Diabetes and hypertension: A position statement by the American diabetes association. Diabetes Care, 40(9), 1273-1284. https://doi.org/10.2337/dci17-0026 
Drozdz, D., \& Kawecka-Jaszcz, K. (2014). Cardiovascular changes during chronic hypertensive states. Pediatric Nephrology (Berlin, Germany), 29(9), 1507-1516. https://doi.org/10.1007/s00467-013-2614-5

Fezeu, L., Kengne, A. P., Balkau, B., Awah, P. K., \& Mbanya, J. C. (2010). Ten-year change in blood pressure levels and prevalence of hypertension in urban and rural Cameroon. Journal of Epidemiology and Community Health, 64(4), 360-365. https://doi.org/10.1136/jech.2008.086355

IHME. (2019). The Lancet: Estimasi - estimasi penyakit global terbaru mengungkapkan badai " sempurna" dari penyakit - penyakit kronis yang timbul dan kegagalan kesehatan publik yang memperbesar intensitas pandemi COVID 19.

Jones, C. M., Baker-Groberg, S. M., Cianchetti, F. A., Glynn, J. J., Healy, L. D., Lam, W. Y., Nelson, J. W., Parrish, D. C., Phillips, K. G., Scott-Drechsel, D. E., Tagge, I. J., Zelaya, J. E., Hinds, M. T., \& McCarty, O. J. T. (2014). Measurement science in the circulatory system. Cellular and Molecular Bioengineering, 7(1), 1-14. https://doi.org/10.1007/s12195-013-0317-4

Kemenkes. (2018). Mencegah dan Mengontrol Hipertensi.

Kemenkes. (2019). Hipertensi si Pembunuh Senyap.

MacDonald, J. G. and T. (2015). Home Blood Pressure Monitoring. EUROPEAN CARDIOLOGY REVIEW, group 1, 95-101.

Mills, K. T., Bundy, J. D., Kelly, T. N., Reed, J. E., Kearney, P. M., Reynolds, K., Chen, J., \& He, J. (2016). Global Disparities of Hypertension Prevalence and Control: A Systematic Analysis of Population-Based Studies From 90 Countries. Circulation, 134(6), 441-450. https://doi.org/10.1161/CIRCULATIONAHA.115.018912

Mozos, I. (2015). Mechanisms linking red blood cell disorders and cardiovascular diseases. BioMed Research International, 2015. https://doi.org/10.1155/2015/682054

Naidu, B. M., Yusoff, M. F. M., Abdullah, S., Musa, K. I., Yaacob, N. M., Mohamad, M. S., Sahril, N., \& Aris, T. (2019). Factors associated with the severity of hypertension among Malaysian adults. PLoS ONE, 14(1), 1-16. https://doi.org/10.1371/journal.pone.0207472

Oparil, S., Acelajado, M. C., Bakris, G. L., Berlowitz, D. R., Cífková, R., Dominiczak, A. F., Grassi, G., Jordan, J., Poulter, N. R., Rodgers, A., \& Whelton, P. K. (2018). Hypertension. Nature Reviews Disease Primers, 4. https://doi.org/10.1038/nrdp.2018.14

Peltzer, K., \& Pengpid, S. (2018). The Prevalence and Social Determinants of 
Hypertension among Adults in Indonesia: A Cross-Sectional Population-Based National Survey. International Journal of Hypertension, 2018. https://doi.org/10.1155/2018/5610725

Petrie, J. R., Guzik, T. J., \& Touyz, R. M. (2018). Diabetes, Hypertension, and Cardiovascular Disease: Clinical Insights and Vascular Mechanisms. Canadian Journal of Cardiology, 34(5), 575-584. https://doi.org/10.1016/j.cjca.2017.12.005

Pugh, D., Gallacher, P. J., \& Dhaun, N. (2019). Management of Hypertension in Chronic Kidney Disease. Drugs, 79(4), 365-379. https://doi.org/10.1007/s40265019-1064-1

Sharma, P. (2009). Peripheral arterial disease in the elderly. Reichel's Care of the Elderly: Clinical Aspects of Aging, Sixth Edition, 2(4), 123-131. https://doi.org/10.1017/CBO9780511575952.013

Sharman, J. E., Howes, F. S., Head, G. A., McGrath, B. P., Stowasser, M., Schlaich, M., Glasziou, P., \& Nelson, M. R. (2016). How to measure home blood pressure: Recommendations for healthcare professionals and patients. Australian Family Physician, 45(1), 31-34.

Sheppard, J. P., Tucker, K. L., Davison, W. J., Stevens, R., Aekplakorn, W., Bosworth, H. B., Bove, A., Earle, K., Godwin, M., Green, B. B., Hebert, P., Heneghan, C., Hill, N., Hobbs, F. D. R., Kantola, I., Kerry, S. M., Leiva, A., Magid, D. J., Mant, J., ... Mcmanus, R. J. (2020). Self-monitoring of Blood Pressure in Patients with Hypertension-Related Multi-morbidity: Systematic Review and Individual Patient Data Meta-analysis. American Journal of Hypertension, 33(3), 243-251. https://doi.org/10.1093/ajh/hpz182

Sreekanth, K. V., Alapan, Y., Elkabbash, M., \& Ilker, E. (2016). Blood Pressure Checks and Diagnosing Hypertension (BPCHECK): Design and Methods of a Randomized Controlled Diagnostic Study Comparing Clinic, Home, Kiosk, and 24-Hour Ambulatory BP Monitoring. Nature Materials, 15(6), 621-627. https://doi.org/10.1016/j.cct.2019.01.003.Blood

Thimbleby, H. (2013). Technology and the future of healthcare. Journal of Public Health Research, 2(e28), 160-167. https://doi.org/10.1016/0039-6257(81)900813

Widiyanto, A., Putri, S. I., Fajriah, A. S., \& Atmojo, J. T. (2021). Prevention of Hypertension at Home. Journal for Quality in Public Health, 4(2), 301-308. https://doi.org/10.30994/jqph.v4i2.222 